\title{
Comparative effect of garlic (Allium sativum), onion (Allium cepa), and black seed (Nigella sativa) on gastric acid secretion and gastric ulcer
}

This article was published in the following Dove Press journal:

Research and Reports in Medicinal Chemistry

28 November 201I

Number of times this article has been viewed

\author{
Naheed Amir \\ Amina Al Dhaheri \\ Najla Al Jaberi \\ Fatma Al Marzouqi \\ Salim MA Bastaki \\ Department of Pharmacology \\ and Therapeutics, Faculty of \\ Medicine and Health Sciences, \\ UAE University, Al Ain, United \\ Arab Emirates
}

Correspondence: Salim MA Bastaki Department of Pharmacology, Faculty of Medicine and Health Sciences, UAE University, PO Box 17666, Al Ain, United Arab Emirates

Tel +971 37137520

Fax +97I 37672033

Email sbastaki@uaeu.ac.ae

\begin{abstract}
Protective roles of raw and boiled garlic (Allium sativum) and onion (Allium cepa) in comparison with black seed (Nigella sativa) on acidified ethanol-induced gastric ulcers and gastric acid secretion in rats in vivo have been investigated. Raw or boiled Nigella sativa, garlic, or onion significantly inhibited histamine stimulated acid secretion, whereas on basal acid secretion, onion and garlic significantly stimulated secretion but Nigella sativa had no effect. Raw Nigella sativa and garlic showed a significant decrease in the ulcer index when compared with the control at all doses $(0.25 \mathrm{~g} / \mathrm{kg}, 0.5 \mathrm{~g} / \mathrm{kg}$, and $1 \mathrm{~g} / \mathrm{kg})$ tested, whereas onion-only, at doses of $0.5 \mathrm{~g} / \mathrm{kg}$ and $1 \mathrm{~g} / \mathrm{kg}$, significantly reduced the ulcer index. Boiled Nigella sativa showed equal potency to raw Nigella sativa in decreasing ulcer index, but boiled garlic and onion showed reduced potency. The results of this study demonstrate the protective role of raw Nigella sativa, garlic, and onion against ethanol-induced gastric ulcers and gastric acid secretion. Boiling did not affect the protective effect of Nigella sativa on gastric ulcers.
\end{abstract}

Keywords: Nigella sativa, onion, garlic, acid ulcer

\section{Introduction}

Nigella sativa (NS) (black seed or black cumin), garlic, and onion have been used as food and for medicinal purposes since ancient times. Nigella sativa Linn., a plant belonging to the family Ranunculaceae, is cultivated throughout India, Pakistan, and countries bordering the Mediterranean Sea and other tropical countries, and grows as a small herb. ${ }^{1-3}$ This plant is one of the most widely studied. ${ }^{4}$ In fact, these common food plants are a rich source of several nutrients that are used in the treatment and prevention of a number of diseases, including cancer, coronary heart disease, obesity, diabetes, hypertension, and disturbances of the gastrointestinal tract. ${ }^{5-7}$ Similarly, garlic (Allium sativum) and onion (Allium cepa) are among the oldest of all cultivated plants and form an important dietary and medicinal role. Garlic has been used as a spice, food, and folklore medicine for over 4000 years. ${ }^{8}$ Garlic has been mentioned many times in the Codex Ebers, an Egyptian medical papyrus dating to about $1500 \mathrm{BC}$, regarding its effectiveness for a variety of ailments, including heart problems, headache, bites, worms, and tumors. ${ }^{9}$ In China, garlic and onion tea have long been recommended for many ailments, including fever, headache, cholera, and dysentery. More recent studies have shown garlic to be effective in lowering serum cholesterol $^{10,11}$ and to have protective effects against stroke, coronary thrombosis, ${ }^{12,13}$ atherosclerosis, ${ }^{14,15}$ platelet aggregation, ${ }^{16,17}$ infections, and vascular disorders. ${ }^{13}$ Garlic has also been reported to have fibrinolytic activity in both humans ${ }^{18}$ and 
experimental animals. ${ }^{10}$ Similarly, onion has been shown to have serum cholesterol-lowering properties ${ }^{10,11}$ and to have protective effects against platelet aggregation induced by epinephrine, adenosine diphosphate, or arachidonic acid. ${ }^{16,19,20}$ Some studies have shown the gastroprotective effect of NS oil, ${ }^{21,22}$ and one study ${ }^{23}$ has shown garlic to be protective against ethanol-induced gastric ulcers. However, there is a paucity of studies of garlic on gastric ulcers, and no information is available on the effects of onion on the gastrointestinal tract. Similarly, there is a paucity of studies on gastric acid secretory effect of garlic, onion, and NS. Therefore, our main aim was to investigate the protective role of raw or boiled garlic and onion on acidified ethanolinduced gastric ulcers and histamine-stimulated gastric acid secretion in rats and to compare them with either raw or boiled NS.

\section{Materials and methods}

Male Wistar rats (weighing 200-225 g) were fasted for 24 hours in wire mesh cages to avoid coprophagy. The rats were obtained from the animal facilities of the Faculty of Medicine and Health Sciences of the United Arab Emirates (UAE) University.

\section{Materials}

Onion, NS, and garlic were obtained from the local market. Hydrochloric acid $(\mathrm{HCl})$, ethanol, and histamine were obtained from Sigma (St Louis, MO).

\section{Gastric acid secretion measured in vivo}

Four groups of six rats were used for the experiment. Rats were initially anesthetized with urethane $(1.5 \mathrm{~g} / \mathrm{kg})$ intraperitoneally. Following general anesthesia, a laparotomy was immediately performed followed by the insertion of a polyethylene tube at the pyloric end of the stomach. This tube was used to collect exudates from the stomach. An orogastric tube was inserted in the stomach via the esophagus. This tube was used to perfuse the stomach with saline $(\mathrm{pH} 7)$ at a constant rate of $7 \mathrm{~mL} / \mathrm{min}^{-1}$ at $37^{\circ} \mathrm{C}$. Following perfusion, effluent samples were collected and titrated against $0.01 \mathrm{M} \mathrm{NaOH}$ every 15 minutes for acid secretion. After basal acid output for 1 hour, saline, raw, or boiled homogenized water extracts ( 5 minutes) of test drugs (either NS, onion, or garlic; six rats for each dose) at neutral $\mathrm{pH}$ was administered orally to the animals. Thirty minutes later, histamine $\left(2 \mathrm{mg} / \mathrm{kg}^{-1}\right)$ was administered as a bolus injection. Acid output was monitored continuously for 2 hours thereafter. The acid output was calculated and expressed as $\mu \mathrm{mol}\left(15 \mathrm{~min}^{-1}\right)$. This study had an ethical clearance from the Ethical Committee of the UAE University.

\section{Antiulcer activity}

Rats were divided into four groups of six to seven animals for each experiment. Each group received either neutral $\mathrm{pH}$ physiologic saline $(1 \mathrm{~mL})$ or water extract of either raw or boiled ( 5 minutes) homogenized NS, garlic, or onion $(0.25 \mathrm{~g} / \mathrm{kg}, 0.5 \mathrm{~g} / \mathrm{kg}$, or $1 \mathrm{~g} / \mathrm{kg}$; six rats for each dose) by gastric gavage. After 30 minutes of the treatment, $1 \mathrm{~mL}$ of acidified ethanol (60\% ethanol with $150 \mathrm{mM} \mathrm{HCl})$, an ulcerogenic agent, was administered orally to the animals. The animals were sacrificed 1 hour later by overdosing with pentobarbital. The abdomen was incised, and the stomachs removed, cut open along the greater curvature, and rinsed with saline to remove any adherent particles and mucus. The open stomach was spread on a sheet of cork so as to have a clear view of gastric lesions in the gastric mucosa. The total lengths of hemorrhagic lesions, which were approximately $1 \mathrm{~mm}$ in length and formed in the glandular portion of the gastric mucosa, were taken as ulcer index. An observer who was unaware of the drug treatments confirmed the ulcer index. The percentage reduction of the ulcer index in the drug-treated groups was calculated from the salinetreated groups.

The use of $60 \%$ ethanol in $150 \mathrm{mM} \mathrm{HCl}$ to produce an ulcerogenic effect was based on earlier observation that ethanol $50 \%$ and over provided a reproducible model of gastric damage. ${ }^{24,25}$

\section{Statistical analysis}

The results are mean plus standard error of the mean. Differences were compared using one-way analysis of variance. Significance differences were determined by paired Student's $t$-tests. Significance was set at $P<0.05$.

\section{Results Effect of either raw or boiled NS, garlic, or onion on gastric acid secretion}

Figure 1 shows the effect of gastric gavage of either raw NS $(0.25 \mathrm{~g} / \mathrm{kg})$, garlic $(0.5 \mathrm{~g} / \mathrm{kg})$, or onion $(0.5 \mathrm{~g} / \mathrm{kg})$ on gastric acid secretion administered 30 minutes before histamine $(\mathrm{n}=6)$. There was an initial significant $(P>0.001)$ increase in basal acid secretion by both onion and garlic followed by significant $(P>0.01-0.001)$ inhibition of histaminestimulated gastric acid secretion after 45-90 minutes of administration. NS did not inhibit basal gastric acid secretion 

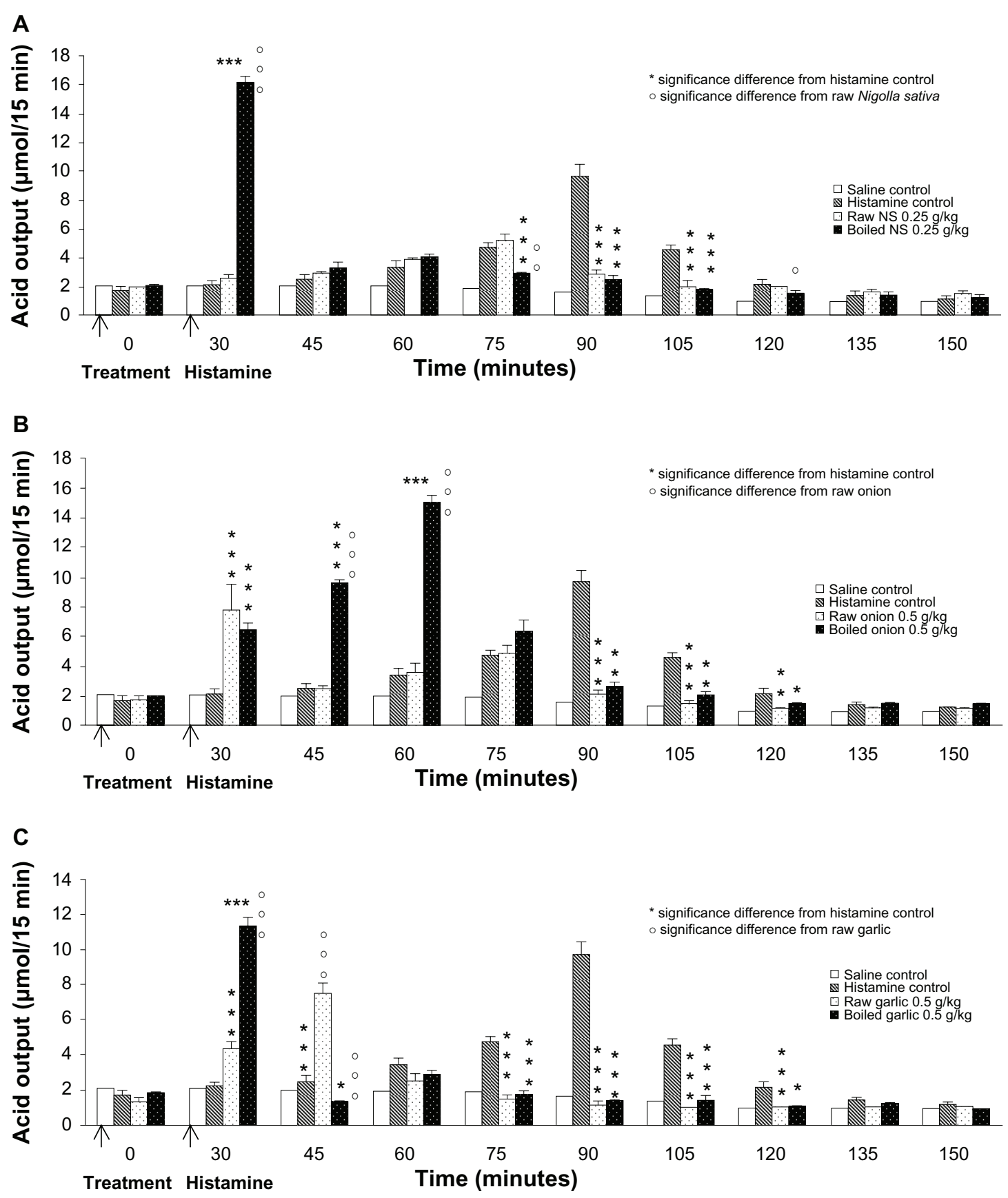

Figure I Effect of raw and boiled Nigella sativa $(0.25 \mathrm{~g} / \mathrm{kg})(\mathbf{A})$, onion $(0.5 \mathrm{~g} / \mathrm{kg})(\mathbf{B})$, and garlic $(0.5 \mathrm{~g} / \mathrm{kg})(\mathbf{C})$ on gastric acid secretion in the stomachs of rats administered 30 minutes before histamine.

Notes: The results are mean \pm standard error of the mean of six experiments. Significant difference $* P>0.05, * * P>0.01, * * * P>0.001$ for histamine control; ${ }^{\circ 0 \circ} P>0.00$ I, ${ }^{\circ} \mathrm{P}>0.0,{ }^{\circ} \mathrm{P}>0.05$ for boiled from raw Nigella sativa, onion, and garlic.

but inhibited histamine-stimulated acid secretion after 60-75 minutes of histamine administration. There was some visual observation increase in salivary secretion after the administration of garlic and onion.

After boiling the test food products in water for 5 minutes, there was an initial significant $(P>0.001)$ increase in basal acid secretion by onion, garlic, and NS followed by significant $(P>0.01-0.001)$ inhibition of histamine-stimulated gastric acid secretion after 45-90 minutes of administration.

\section{Effect of either raw or boiled NS, garlic,} or onion on acidified ethanol-induced gastric ulcer

Table 1 summarizes the results of the ulcer study, and Figure 2 shows the photo microns of the effects of either raw or 
Table I Effect of administration of either raw or boiled Nigella sativa, onion (Allium cepa), or garlic (Allium sativum) on acidified ethanolinduced ulcer in rats $(n=7)$

\begin{tabular}{|c|c|c|c|c|c|c|}
\hline \multirow[t]{2}{*}{ Groups } & \multirow[t]{2}{*}{ Dose of the substance } & \multicolumn{2}{|c|}{$\begin{array}{l}\text { Ulcer index (mean } \pm \text { standard } \\
\text { error of the mean) }\end{array}$} & \multicolumn{3}{|l|}{$P$-value } \\
\hline & & Raw & Boiled & Control vs raw & Control vs boiled & Raw vs boiled \\
\hline Control & $10 \mathrm{~mL} / \mathrm{kg}$ & $126.5 \pm|| 1.5$ & $126.5 \pm 11.5$ & & & \\
\hline \multirow[t]{3}{*}{ Nigella sativa } & $0.25 \mathrm{~g} / \mathrm{kg}$ & $13.7 \pm 5$ & $47.8 \pm 19.1$ & 0.000 & 0.001 & 0.952 \\
\hline & $0.5 \mathrm{~g} / \mathrm{kg}$ & $24.5 \pm 7.1$ & $45.3 \pm 4.3$ & 0.000 & 0.000 & 0.018 \\
\hline & $\mathrm{I} g / \mathrm{kg}$ & $15.3 \pm 4.37$ & $3.8 \pm 2.17$ & 0.000 & 0.000 & 0.002 \\
\hline \multirow[t]{3}{*}{ Onion } & $0.25 \mathrm{~g} / \mathrm{kg}$ & $142.3 \pm 19.05$ & $72.2 \pm 13.3$ & 0.493 & 0.013 & 0.018 \\
\hline & $0.5 \mathrm{~g} / \mathrm{kg}$ & $35.5 \pm 9.75$ & $75 \pm 16.0$ & 0.000 & 0.165 & 0.001 \\
\hline & $\mathrm{I} g / \mathrm{kg}$ & $40.4 \pm 10.4$ & $75 \pm 16.04$ & 0.000 & 0.026 & 0.101 \\
\hline \multirow[t]{3}{*}{ Garlic } & $0.25 \mathrm{~g} / \mathrm{kg}$ & $34.3 \pm 12.2$ & $35.5 \pm 14.4$ & 0.000 & 0.005 & 0.031 \\
\hline & $0.5 \mathrm{~g} / \mathrm{kg}$ & $7.7 \pm 2.9$ & $37 \pm 3.7$ & 0.000 & 0.000 & 0.031 \\
\hline & $\mathrm{lg} / \mathrm{kg}$ & $14.5 \pm 2.7$ & $33.5 \pm 3.7$ & 0.000 & 0.000 & 0.049 \\
\hline
\end{tabular}

boiled NS, onion, and garlic on acidified ethanol-induced gastric ulcers. Acidified ethanol administration at a dose of $10 \mathrm{~mL} / \mathrm{kg}$ caused gastric ulceration (UI, 126.5 \pm 11.5 ) in all the animals tested $(n=7)$ (Table 1, Figure 2). Administration of either raw $\mathrm{NS}$ or garlic at all doses significantly reduced the formation of ulcers when rats were given acidified ethanol $(P<0.001)$.
However, onion was found to reduce the ulcer index only at doses of $0.5 \mathrm{~g} / \mathrm{kg}$ and $1 \mathrm{~g} / \mathrm{kg}$. By comparing the mean ulcer index in all doses of the three preparations, a dose of $0.5 \mathrm{~g} / \mathrm{kg}$ was found to be the most potent in both onion and garlic, as it showed the least ulcer formation (see Figure 2). As for NS, the dose of $0.25 \mathrm{~g} / \mathrm{kg}$ showed the highest potency (see Figure 2).

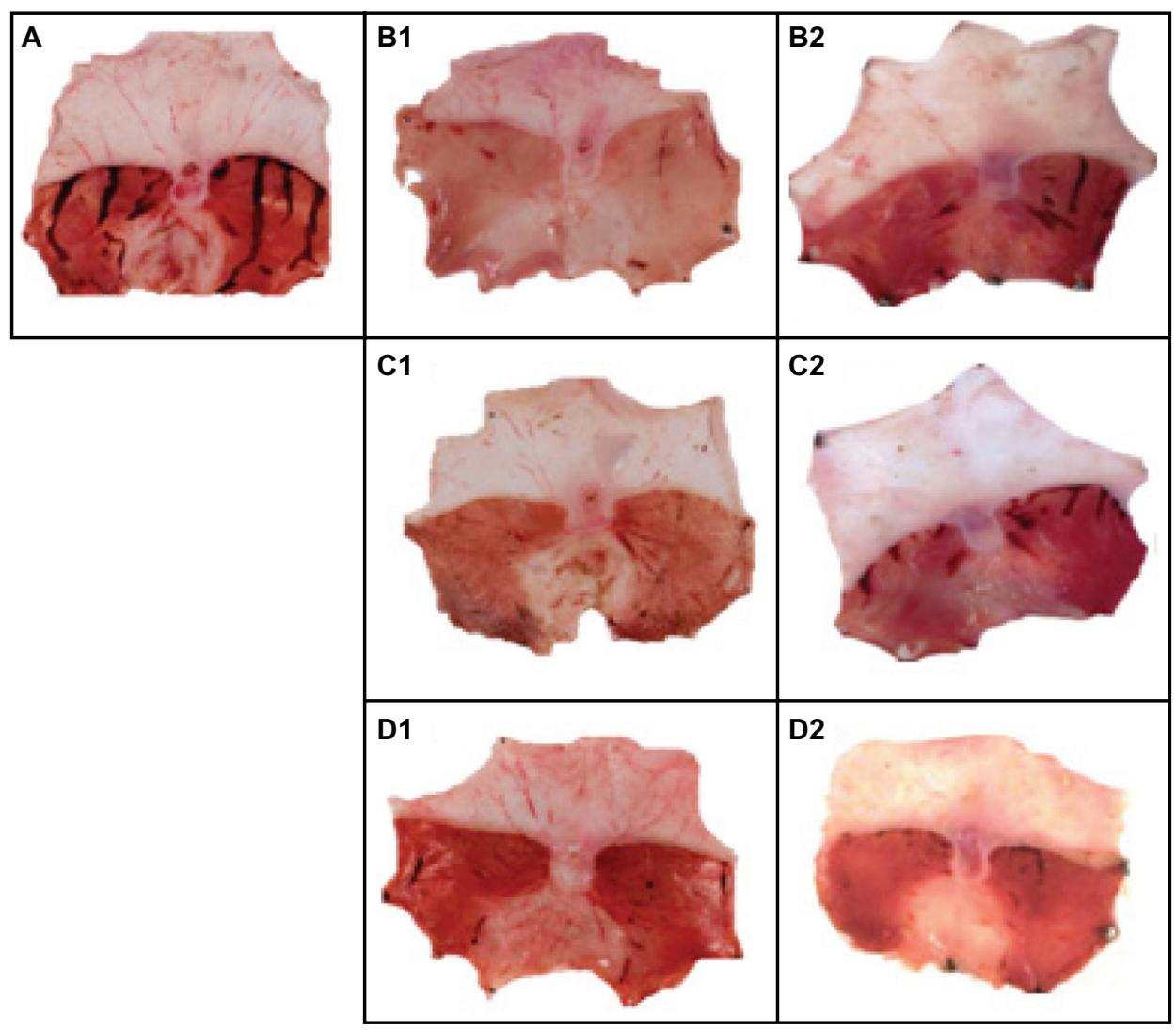

Figure 2 Photomicrographs of stomachs showing the effect of acidified ethanol in (A) control, I (raw) and 2 (boil); (B) Nigella sativa treated, (C) onion treated, and (D) garlic treated.

Notes: Micrographs are the results of six to seven such experiments. ${ }^{a}$ Figures B, C, and D show the most potent doses ( $0.5 \mathrm{~g} / \mathrm{kg}$ in onion and garlic, $0.25 \mathrm{~g} / \mathrm{kg}$ in Nigella sativa) and the most effective in reducing the stomach ulcers in the raw at least. In the boiled, the higher doses were more effective in reducing stomach ulcers (not shown). 
Administration of boiled NS at both doses, $0.5 \mathrm{~g} / \mathrm{kg}$ and $1 \mathrm{~g} / \mathrm{kg}$, significantly $(P<0.001)$ reduced the mean ulcer index similar to the raw NS. Boiled garlic similarly $(P<0.001)$ reduced the mean ulcer index, but the reduction $(37.0 \pm 8.7)$ was much less when compared with the raw garlic $(7.7 \pm 2.9)$ at both doses of $0.5 \mathrm{mg} / \mathrm{kg}$ and $1.0 \mathrm{mg} / \mathrm{kg}$. Boiled onion at a dose of $0.5 \mathrm{~g} / \mathrm{kg}$ did not significantly reduce the mean ulcer index $(72 \pm 16)$ when compared with the control (126.5 \pm 11.5$)$. At $1 \mathrm{~g} / \mathrm{kg}$, boiled onion significantly $(P<0.05)$ reduced the mean ulcer index $(75.0 \pm 16.04)$ when compared with the control but was reduced to a lesser degree when compared with raw onion ( $40.4 \pm 10.4)$. Figure 2 shows the differences in the protective effect of the food herbs on ethanol-induced ulcers. The protective effect was reduced but not abolished.

\section{Discussion}

This study investigated the effects of NS, garlic, and onion on gastric acid secretion and gastric ulcers induced by acidified ethanol. NS had no effect on basal acid secretion but inhibited histamine-stimulated gastric acid secretion. The effect of NS is similar to another report by Rajkumar et $\mathrm{al}^{26}{ }^{26}$ who did the experiment on pyloric ligated stomachs of rats rather than by gastric perfusion. Additionally, Rajkumar et $\mathrm{al}^{26}$ used alcoholic extract of NS rather than saline extract, and no gastric acid secretory stimulant was used. However, El-Dakhankhny et $\mathrm{al}^{21}$ found no significant change in free acidity and peptic activity by NS. As far as the authors are aware, we are the first to report this inhibitory effect of NS on acid secretion by using the gastric perfusion method.

The initial increase in acid secretion by onion and garlic on gastric acid secretion could be due to a cholinergic mechanism since Vasudevan et al, ${ }^{27}$ when working with aqueous spice extracts administered by an intragastric route, increased acid secretion and a cholinergic mechanism was proposed. Other investigators ${ }^{28}$ reported a digestive-stimulating action of spices mixed with onion and found that bile secretion, bile acid, and pancreatic enzymes were significantly increased in spices containing onions. Rafsanjani et $\mathrm{al}^{29}$ found an increase in basal acid secretion and a decline in pentagastrinstimulated acid secretion in rats treated with garlic extracts, which is similar to our results, although we used histamine as the stimulant. They attributed this stimulatory effect to the special components in garlic that either increase parietal or chief cell activities through cholinergic mechanisms. Additionally, we had observed an increase in salivary secretion (visual observation) when the rats were administered, showing that cholinergic mechanisms could be involved.
Our ulcer results show that administration of acidified ethanol produced $100 \%$ ulcer induction in rats with a mean ulcer index of $126.5 \pm 11.5$. It is well known that ethanol causes ulcers and is known to produce gastric mucosal damage within 1-3 minutes of its instillation into the gut, which lasts more than 2 hours by causing areas of focal hyperemia and hemorrhage. ${ }^{30}$ We have also shown in our previous studies that ethanol causes gastric damage in rodents. ${ }^{31,32}$

The results of this study clearly showed that raw NS has a gastroprotective effect against gastric ulcers induced by acidified ethanol. The results are in line with previous reports that $\mathrm{NS}^{21,22}$ protects against ethanol-induced ulcers. El-Dakhankhny et $\mathrm{al}^{21}$ demonstrated that gastric mucin content and glutathione S-transferase (GST) levels were significantly higher and gastric mucosal histamine levels reduced when rats were pretreated with NS oil. An increase in glutathione levels leads to an increase in prostaglandin $E_{2}$ $\left(\mathrm{PGE}_{2}\right)$ levels, because glutathione is a cofactor in some steps of $\mathrm{PGE}_{2}$ synthesis. ${ }^{33}$ In addition, thymoquinone, the main constituent of NS, has been shown to be gastroprotective against ethanol-induced gastric mucosal injury. ${ }^{34,35}$ Fiorucci et $\mathrm{a}^{36}$ investigated the role of hydrogen sulfide $\left(\mathrm{H}_{2} \mathrm{~S}\right)$ in a rat model of nonsteroidal anti-inflammatory drug gastropathy and concluded that $\mathrm{H}_{2} \mathrm{~S}$ has a physiologic role in regulating the gastric microcirculation and gastric mucosal protection. Thus, raised gastric mucin, GST, thymoquinone, and $\mathrm{H}_{2} \mathrm{~S}$ and reduced mucosal histamine could be the mechanism of gastroprotective effect of NS in our study.

Raw garlic and onion showed similar activities in protecting the gastric mucosa against ethanol-induced gastric ulcers. Both were comparable with NS, though NS was more potent $(0.25 \mathrm{~g} / \mathrm{kg}$ for NS against $0.5 \mathrm{~g} / \mathrm{kg}$ for garlic and onion). The protective effect of garlic is in line with one report that shows garlic to be protective against ethanol-induced gastric ulcer. ${ }^{23}$ The gastroprotective effect of onion in this study was remarkable though not totally unexpected. The gastroprotective effect of onion observed in this study is, as far as the authors are aware, the first report of its kind, although onion is known for its other biologic effects such as promoting cardiovascular health by decreasing atherosclerotic or thrombotic disease in populations with increased onion intake. ${ }^{37,38}$ The antiplatelet activity of onion and garlic is determined in part by the native concentration of organosulfur compounds. ${ }^{39}$ As, initially, raw onion and garlic were used in this study, it was interesting to discover the mechanism of their protective effects on the gastric mucosa against ulcers in the present study. One of the mechanisms suggested was its effect on 
the cyclooxygenase activity. Garlic extracts have been shown to decrease serum thromboxane (TX) levels, whereas onion extract has had no effect on TX concentration. ${ }^{40}$ There is convincing evidence that TX is ulcerogenic ${ }^{41}$ and that TXA synthase inhibitors protect against the development of gastric erosions in certain animals. ${ }^{42,43}$ Thus, in this study, a possible mechanism of inhibition of gastric ulcers by garlic could be its ability to inhibit TX formation. Garlic and onion contain the organosulfur compound alkylcysteine and sulfoxides such as S-propenylcysteine sulfoxide (major component), S-propylcysteine sulfoxide, and S-methylcysteine sulfoxide, and in addition propionaldehyde and dipropyl disulfide. ${ }^{44,45}$ Sparnins et $\mathrm{a}^{46,47}$ and Sumiyoshi and Wargovich ${ }^{48}$ studied the effects of oral administration of these compounds on GST activity and found that GST activity increased in all the tissues. Thus, another possible mechanism of the protective effects of garlic and onion on the gastric mucosa is their actions on increasing the GST levels, which is known to increase prostaglandin synthesis and thus cytoprotection.

Because humans often consume garlic and onion in a cooked form, their efficacy as herbs in the prevention of cardiovascular disease and gastric ulcers may be doubtful. Boiled garlic and onion have been shown to have significantly reduced biologic activity. ${ }^{40}$ It was found that boiled garlic and onion showed a reduced effect on platelet aggregation as compared with raw garlic and onion. ${ }^{40}$ Because of these findings, it was decided also to see whether there are any changes in their activities when boiled NS, garlic, or onion are used on ethanol-induced gastric ulcers. We found that, indeed, the effects of garlic and onion on ulcer index were reduced but not completely abolished. Boiling had no effect on the protective effect of NS on gastric ulcer. One can speculate that active ingredients in NS are different from those in garlic and onion, judging from the lack of a reduced effect of boiled NS's protective effect on gastric ulcers. As far as we are aware, no comparative studies have previously been done of the effects of boiled NS, onion, and garlic on ulcer formation. The reduction of the activities when herbal products are cooked is probably due to the alteration of the chemistry of the active ingredients.

\section{Conclusion}

From the results of the study we can conclude that NS, onion, and garlic have a protective effect on acidified ethanolinduced gastric ulcer and gastric acid secretion. Thus, NS, onion, and garlic are beneficial in the prevention of ulcer formation and reduction in acid secretion.

\section{Disclosure}

The authors report no conflicts of interest in this work.

\section{References}

1. Nadkarni KM. Nigella sativa. The Indian Materia Medica. 1982;1: 854-857.

2. Satyavati GV, Gupta AK. Nigella sativa. Medicinal Plants of India. 1987;II:337-340.

3. Jansen PCM. Spices condiments and medicinal plants in Ethiopia. Their taxonomy and agricultural significance. Center for Agricultural Publishing and Documentation, Addis Ababa, 1981:76-85.

4. Akhtar MS, Ali MR. Studies of hypoglycaemic activity of Cumin nigrum seeds in normal and alloxan diabetic rats. Planta Med. 1985: $81-85$.

5. Salomi NJ, Nair SC, Jayawardhanan KK, et al. Antitumour principles from Nigella sativa seeds. Cancer Lett. 1992;1:41-46.

6. El Tahir, Ashour MMS, Al Harbi MM. The cardiovascular actions of the volatile oil of the black seed (Nigella sativa) in rats: elucidation of the mechanism of action. Gen Pharmacol. 1993;24:1123-1131.

7. El-Sayed, NS El-Din. Some pharmacological studies of Nigella sativa. MSc Thesis, Faculty of Pharmacy, Cairo University; 1998.

8. Milner JA. Garlic: its anticarcinogenic and antitumor properties. Nutr Rev. 1996;54:S83-S86.

9. Block E. The chemistry of garlic and onion. Sci Amer. 1985;252: 114-119.

10. Bordia A, Verma SK, Vyas AK, et al. Effect of essential oil of onion and garlic on experimental atherosclerosis in rabbits. Atherosclerosis. 1977;26:379-386

11. Sainani GS, Desai DB, Natu MN, et al. Onion, garlic and experimental atherosclerosis. Jap Heart J. 1979;20:351-357.

12. Ali M, Thomson M, Al-Naqeeb MA, et al. Antithrombotic activity of garlic: its inhibition of the synthesis of thromboxane-TXB2 during infusion of arachidonic acid and collagen in rabbits. Prostagl Leukot Essent Fatty Acids. 1990;41:95-99.

13. Bordia T, Mohammed N, Thomson M, Ali M. An evaluation of garlic and onion as antithrombotic agents. Prostaglandins Leukot Essent Fatty Acids. 1996;54:183-186.

14. Fudler S. Garlic and prevention of cardiovascular disease. Cardiol Pract. 1989;7:3-30.

15. Turner M. Garlic and circulatory disorders. J Royal Soc Health. 1994; 110:390.

16. Makheja AN, Bailey JM. Antiplatelet constituents of garlic and onion. Agents Action. 1990;29:360-364.

17. Srivastava KC, Tayagi OD. Effects of garlic derived principle (Ajoene) on aggregation and arachidonic acid metabolism in human platelets. Prostagl Leukot Essent Fatty Acids. 1993;49:587-595.

18. Bordia A, Joshi HK, Sanadhya YK, Bhu N. Effect of essential oil of garlic on serum fibrinolytic activity in patients with coronary artery disease. Atherosclerosis. 1977;28:155-159.

19. Srivastava KC. Onion exerts antiaggregatory effects by altering arachidonic acid metabolism in platelets. Prostagl Leukot Med. 1986;24:43-50.

20. Makheja AN, Vanderhoek JY, Bryant RW, Bailey JM. Altered arachidonic acid metabolism by onion and garlic extracts. In: Samuelsson B, Ramwell PW, Baoletti R, editors. Adv Prost Thrombox Res. New York: Raven Press; 1980:309.

21. El-Dakhankhny M, Barakat M, Abd El-Halim M, Aly SM. Effects of Nigella sativa oil on gastric acid secretion and ethanol-induced ulcer in rats. J Ethnopharmacol. 2000;72:299-304.

22. Kanter M, Demir H, Krakaya C, Ozbek H. Gastroprotective activity of Nigella sativa oil and its constituents, thymoquinone against acute alcohol-induced gastric mucosal injury in rats. $W J$ Gastroenterol. 2005;11(42):6662-6666.

23. Khosla P, Karan RS, Bhargaya VK. Effect of garlic oil on ethanolinduced gastric ulcers in rats. Phytother Res. 2004;18(1):87-91. 
24. Nishida A, Takinami Y, Yuki H, et al. YM022 \{(R)-1-[2,3-dihydro-1(2-methylphenyacyl)-2-oxo-5-phenyl-H-1,4-benzodiazepin-3-yl]-3(methyphenyl) urea, a potent and selective gastrin/cholecystokinin-B receptor antagonist, prevents gastric and duodenal lesions in rats. J Pharmacol Exp Ther. 1994;270:1256-1261.

25. Mercer DW, Cross JM, Barreto JC, et al. Cholecystokinin is a potent protective agent against alcohol-induced gastric injury in the rat. Dig Dis Sci. 1995;40:651-660.

26. Rajkumar B, Anandan R, Jayakar B. Anti-ulcer effect of Nigella sativa Linn. against gastric ulcers in rats. Curr Sci. 2002;82(2):177-179.

27. Vasudevan K, Vember S, Veeraghavan K, Haranath PS. Influence of intragastric perfusion of aqueous spice extract on acid secretion in anesthetized albino rats. Indian J Gastroenterol. 2000;19(2):53-56.

28. Patel K, Rao A, Saraswathi G, Srinivasan K. Digestive stimulant action of three Indian spice mixes in experimental animals. Nahrung. 2002; $46(6): 394-398$.

29. Rafsanjani FN, Shahrani M, Vahedian J. Garlic effects on gastric acid and pepsin secretions in rat. Pak Med Sci. 2006;22:1-7.

30. Lacy ER, Ito S. Microscopic analysis of ethanol damage to rat gastric mucosa after treatment with a prostaglandin. Gastroenterology. 1982;83:619-625.

31. Bastaki SMA, Chandranath SI, Singh J. Comparison of the antisecretory and antiulcer activity of epidermal growth factor, urogastrone and transforming growth factor alpha and its derivative in rodents in vivo. Mol Cell Biochem. 2002;236:83-94.

32. Bastaki SMA, Hasan MY, Chandranth SI, et al. PD-136450: A CCK2 (gastrin) receptor antagonist with antisecretory, anxiolytics and antiulcer activity. Mol Cell Biochem. 2003;252:83-90.

33. Shen TY. Prostaglandin synthetase inhibitors. In: Vane JR, Ferreira SH, editors. Handbook of experimental pharmacology. Berlin: SpringerVerlag; vol. 50/11:305-347.

34. Sakamaki H, Akezawa S, Ishibashi M, et al. Significance of glutathione-dependent antioxidant systems in diabetes-induced embryonic malformation. Diabetes. 1999;48(5):1138-1144.

35. El-Abhar HS, Abdallah DM, Saleh S. Gastroprotective activity of Nigella sativa oil and its constituent, thymoquinone, against gastric mucosal injury induced by ischaemia/reperfusion in rats. J Ethnopharmacol. 2003;84:51-258.

36. Fiorucci S, Antonelli E, Distrutti E, et al. Inhibition of hydrogen sulfide generation contributes to gastric injury caused by inflammatory nonsteroidal drugs. Gastroenterology. 2005;129(4):1210-1224.
37. Kanter M, Coskun O, Uysal $\mathrm{H}$. The antioxidative and antihistaminic effect of Nigella sativa and its major constituent, thymoquinone on ethanol-induced gastric mucosal damage. Arch Toxicol. 2006;80(4): 217-224.

38. Kendler BS. Garlic (Allium sativum) and onion (Allium cepa): a review of their relationship to cardiovascular disease. Prev Med. 1987; 16:670-685.

39. Ali M, Bordia T, Mustafa T. Effect of raw versus boiled aqueous extract of garlic and onion on platelet aggregation. Prostaglandins Leukot Essent Fatty Acids. 1999;60:43-47.

40. Goldman IL, Kopelberg M, Debaene JEP, Schwartz BS. Antiplatelet activity of onion (Allium cepa) is sulfur dependent. Thromb Haemost. 1996;54:183-186.

41. Esplugues JV, Whittle BJR. Close-arterial administration of the thromboxane mimetic U-46619 induces damage to the rat gastric mucosa Prostaglandins. 1990;35:137-144.

42. Konturek SJ, Brzozowski T, Piatucki I, et al. Role of prostaglandin and thromboxane biosynthesis in gastric necrosis produced by taurocholate and ethanol. Dig Dis Sci. 1983;28:154-160.

43. Parmar NS, Tariq M, Ageel AM. Effect of thromboxane $A_{2}$ and leukotrienes $\mathrm{C} 4$ inhibitors on the experimentally induced gastric lesions in the rat. Res Commun Chem Pathol Pharmacol. 1987;58:15-25.

44. Edwards SJ, Musker D, Collins HA, Britton G. The analysis of S-alk(en)yl-L-cysteine sulphoxides (flavor precursors) from species of Allium by high performance liquid chromatography. Phytochem Anal. 1994;5:4-9.

45. Virtanen AI, Matikkala EJ. The isolation of S-methyl-L-cysteinesulphoxide and S-n-propyl-L-cysteine sulphoxides from onion (Allium серa) and the antibiotic activity of crushed onion. Acta Chem Scand. 1976;13:1898-1900.

46. Sparnins VL, Mott AW, Wattenberg LW. Effects of Allyl methyl trisulfide on glutathione S-transferase activity and BO-induced neoplasia in the mouse. Nutr Cancer. 1986;9:171-176.

47. Sparnins VL, Barany G, Wattenberg IW. Effects of organosulfur compounds from garlic and onions of benzopyrone-induced neoplasia and glutathione S-transferase activity in the mouse. Carcinogenesis. 1988;9:131-134

48. Sumiyoshi H, Wargovich MJ. Garlic (Allium sativum): a review of its relationship to cancer. Asia Pacific J Pharmacol. 1989;4:133-140.
Research and Reports in Medicinal Chemistry

\section{Publish your work in this journal}

Research and Reports in Medicinal Chemistry is an international, peerreviewed, open access journal publishing original research, reports, reviews and commentaries on all areas of medicinal chemistry. The manuscript management system is completely online and includes a very quick and fair peer-review system, which is all easy to use.

\section{Dovepress}

Visit http://www.dovepress.com/testimonials.php to read real quotes from published authors. 